\title{
Nuevo ordenamiento de la Carrera de Secretarios comunales y provinciales en Italia $\left(^{*}\right)$
}

En una de sus sesiones, la Comisión interna de la Cámara aprobó un proyecto de ley sobre el nuevo ordenamiento de la Carrera de Secretarios comunales y provinciales, que viene a modificar el estado jurídico y el ordenamiento de dicha Carrera.

Cada día es mayor la vitalidard y las exigencias de los Entes locales. Esto se traduce en un incremento de los graves deberes que vienen a recaer en la clase secretarial. Por ello, la disposición aprobada por ła Comisión de la Cámara italiana viene a constituir un nuevo reconocimiento de los derechos de esa clase, que, con preparación, lignidad $\gamma$ sentido de la responsabilidad, sabe llevar el peso de: tale: deberes.

La Cámara sabe que, aun no habiendo logrado esta disposición la perfección e idoneidad que todos desean, es, sin embargo, entre las disposiciones positivas, la más factible hasta nuestros días.

Sabe también que pana recoger otras mejoras, hubieran sido necesarias nuevas dilaciones al objeto de hallar una solución que no constituyese un grave peso sobre las Administraciones locales. $\because$

\section{Clases}

Conforme al comentado proyecto de ley, los Secretarios comunales y provinciales pueden ser:

(*) Hemos utilizado para este trabajo la "RIVIsta Amministratriva DELla REPUBblica ITALIANA", núms. 8-9, agosto-septiẹmbre, 1961, páginas 473 y ss. 


\section{A) Secretarios comunales}

$1^{\circ} .^{\circ}$ Secretario General Comunal de $1^{3}$ clase,

2. ) Secretario Generail Comunal de 2." clase,

$\left.3 .^{\circ}\right)$ Secretario Comunal Jefe de.$^{a}$ clase,

$4 .^{\circ}$ ) Secretario Comunal Jefe de $2 .^{a}$ clase,

$5^{\circ}$ ) Secretario Comunal de $1 .^{\text {a }}$ clase, y

$\left.6 .{ }^{\circ}\right)$ Secretario Comunal de $2 .^{\circ}$ clase.

Los primeros prestan sus servicios en las Comunas cuyo censo de población abarca de 65.001 a 250.000 habitantes, o en las Capitales de Provincia de más de 40.000 habitantes; los segundos, son los que pertenecen a las plantillas de las Comunas que tienen un censo de 30.001 a 65.000 habitantes y a las de Capitales de Provincia de menos de 40.c00 habitantes; los terceros desempeñan las Secretarías de poblaciones de 8.001 a 30.000 habitantes: los cuartos pertenecen a Ayuntamientos de más de 4.000 habitantes, y los quintos y sextos a los de menos de 4.000 habitantes.

\section{B) Secretarios provinciales}

.$\left.^{\circ}\right)$ Secretario Provincial General de $1 .^{*}$ clase y

2. ${ }^{\circ}$ Secretario Provincial General de $2 .^{\circ}$ clase.

Los primeros desempeñan sus funciones en aquellas Provincias cuya Capital tenga más de $\mathbf{2 5 0 . 0 0 0}$ habitantes, o bien que teniendo un censo de población comprendido entre los 40.000 y 250.000 habitantes, sin embargo, la población comprendida en la Provincia sea superior a 400.000 habitantes, o cuando dicha población sea de 300.000 a 400.000 habitantes siendo el territorio provincial superior a los $4.000 \mathrm{ki}$ lómetros cuadrados.

Los segundos se asignan a todas las demás Provincias.

\section{4signaciones}

All Secretario general comunal de $10^{\circ}$ clase, que desempeña sus funciones en das Comunas de clase I-A, se le reconoce el coeficiente 759 , con un estipendio inicial de 2.277 .000 liras, mientras al 


\section{CRONICAS}

Secretario general de $I^{2}{ }^{2}$ dase que presta sus servicios en una Comuna de categoría I-B, se le reconoce el coeficiente 670 que equivale a un estipendio inicial anual de 2.0ro.000 liras. Al Secretario general de segunda clase se le reconoce un coeficiente de 500 , que corresponde a un haber de $\mathbf{1} .500 .000$ liras anuales.

A los Secretarios comunales jefes de $1 .^{a}$ y $2 .^{\text {a }}$ clase se le atribuyen respectivamente los coeficientes 402 y 325 , que corresponden a haberes anuales de $\mathbf{1} .206 .000$ y 975.000 liras respectivamente. Finalmente, a los Secretarios comunales de $1 .^{\mathrm{a}}$ y $2 .^{3}$ clase se les atribuyen los coeficientes 271 y 229, que corresponden a haberes anuales iniciales de $8 \mathrm{I} 3.000$ y 687.000 liras.

\section{RESUMEN RELATIVO A SECRETARIOS COMUNALES}

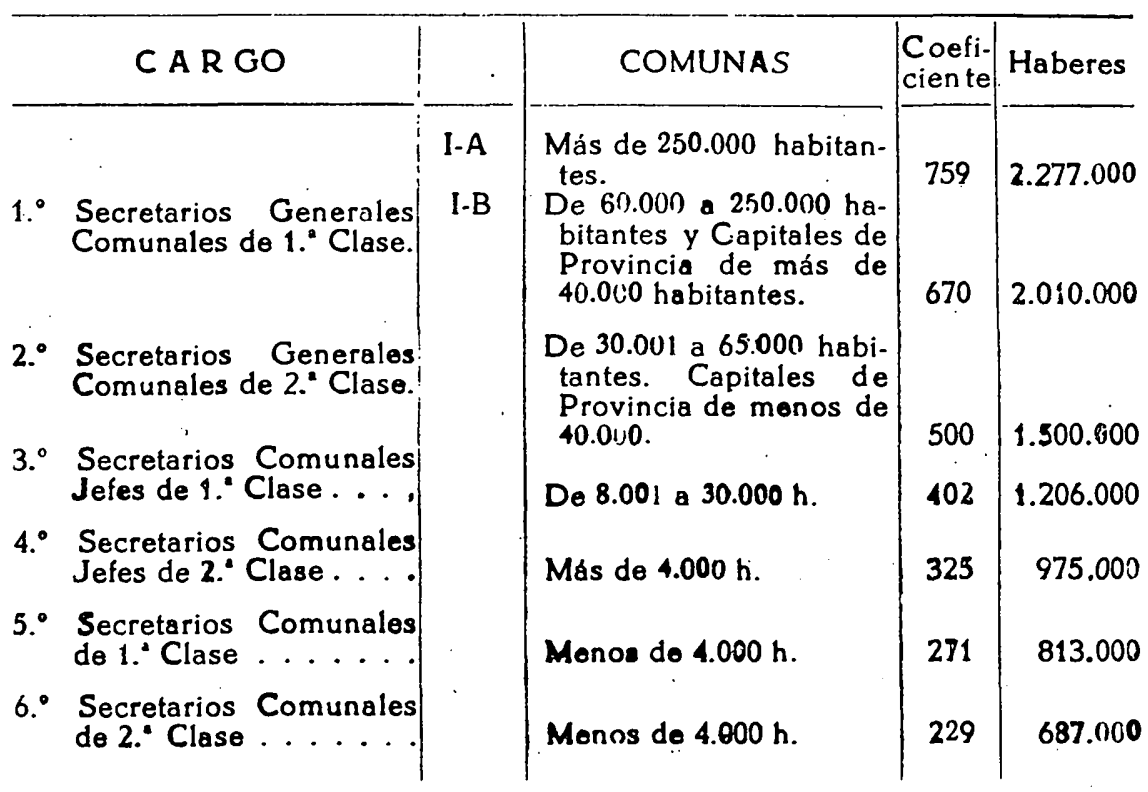

Gumersindo GuerRa-Librero 